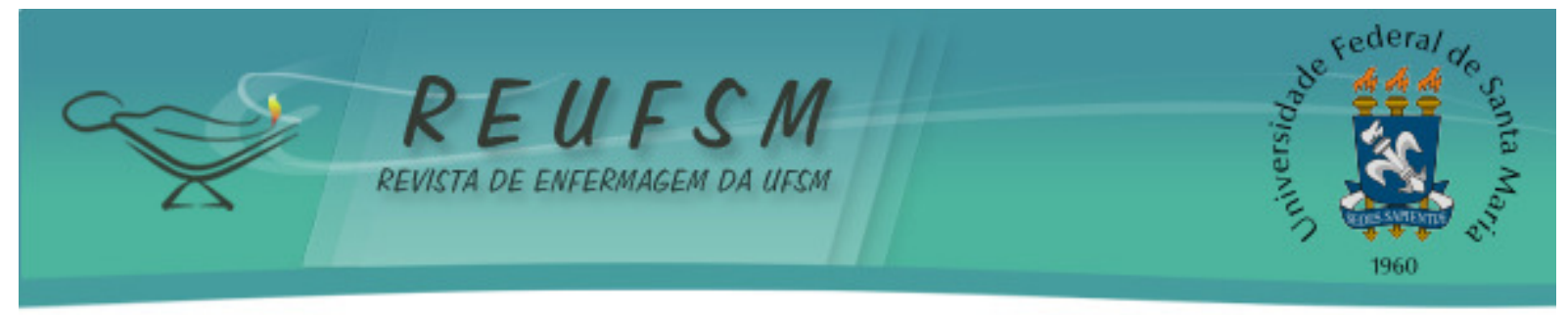

ARTIGO ORIGINAL

\title{
MITOS E DÚVIDAS DE ADOLESCENTES ACERCA DAS MODIFICAÇOES CORPORAIS E SUAS IMPLICAÇOES NA SEXUALIDADE
}

\author{
MYTHS AND DOUBTS OF TEENAGE WOMEN ABOUT BODY MODIFICATIONS AND THEIR \\ IMPLICATIONS ON SEXUALITY
}

\section{MITOS Y DUDAS DE ADOLESCENTES SOBRE MODIFICACIONES CORPORALES Y SUS IMPLICACIONES EN LA SEXUALIDAD}

Doi: $10.5902 / 2179769210812$

\author{
Silvana Cruz da Silva ${ }^{1}$ \\ Lisie Alende Prates ${ }^{2}$ \\ Juliane Scarton ${ }^{3}$ \\ Camila Nunes Barreto ${ }^{4}$ \\ Camila Neumaier Alves ${ }^{5}$ \\ Laís Antunes Wilhelm ${ }^{6}$ \\ Lúcia Beatriz Ressel $^{7}$
}

RESUMO: Objetivo: conhecer os mitos e as dúvidas de um grupo de mulheres adolescentes em relação às modificações corporais e suas implicações na sexualidade. Método: estudo de campo, do tipo descritivo, com abordagem qualitativa. As participantes do estudo foram nove adolescentes do sexo feminino. Os dados foram coletados em uma escola pública de ensino fundamental de um município do Rio Grande do Sul, por meio da técnica do grupo focal e analisados conforme a análise de conteúdo temática. Resultados: os eventos femininos mais comuns no grupo foram relacionados à menstruação, como a tensão pré-menstrual, a menarca e a virgindade. Entendeu-se que os mesmos são dotados de significados socioculturais construídos no convívio social das adolescentes. Conclusão: o estudo possibilitou um melhor entendimento sobre a influência da cultura na vivência da sexualidade, demonstrando a importância de buscar, junto às adolescentes, sua compreensão, seus significados, mitos e dúvidas.

Descritores: Saúde do adolescente; Saúde da mulher; Sexualidade; Cultura; Enfermagem.

ABSTRACT: Aim: to know the myths and doubts of a group of teenage women in relation to body changes and their implications on sexuality. Method: descriptive field study, with a qualitative approach. The participants of the study were nine female teenagers. The data were collected in a public elementary school in a city of Rio Grande do Sul through the focal group technique, and analyzed according to the content analysis. Results: the most common female events in the group were related to menstruation, such as the premenstrual syndrome, menarche and virginity. It was considered that they are gifted with sociocultural meanings constructed in social conviviality of adolescents. Conclusion: the study enabled a better understanding of the influence of culture in the experience of sexuality, demonstrating the importance of seeking, along with teenagers, their

\footnotetext{
${ }^{1}$ Enfermeira. Mestra em Enfermagem pela Universidade Federal de Santa Maria (UFSM). Santa Maria/Rio Grande do Sul(RS)/Brasil. E-mail: silvanacruzufsm@yahoo.com.br

${ }^{2}$ Enfermeira. Mestranda em Enfermagem pela UFSM. Santa Maria, RS/Brasil. E-mail: lisiealende@hotmail.com

${ }^{3}$ Enfermeira. Mestranda em Enfermagem pela UFSM. Santa Maria/RS/Brasil. E-mail: juliscarton10@hotmail.com

${ }^{4}$ Enfermeira. Mestranda em Enfermagem pela UFSM. Santa Maria/RS/Brasil. E-mail: camilabarreto_6@msn.com

${ }^{5}$ Enfermeira. Mestranda em Enfermagem pela UFSM. Santa Maria/RS/Brasil. E-mail: camilaenfer@gmail.com

${ }^{6}$ Enfermeira. Doutoranda em Enfermagem pela UFSM. Santa Maria/RS/Brasil. E-mail: laiswilhelm@gmail.com

${ }^{7}$ Enfermeira Doutora em Enfermagem pela Universidade de São Paulo (USP). Docente da graduação do curso de Enfermagem e da pós-graduação do Programa de Pós-Graduação em Enfermagem da UFSM. E-mail: lbressel208@yahoo.com.br
} 


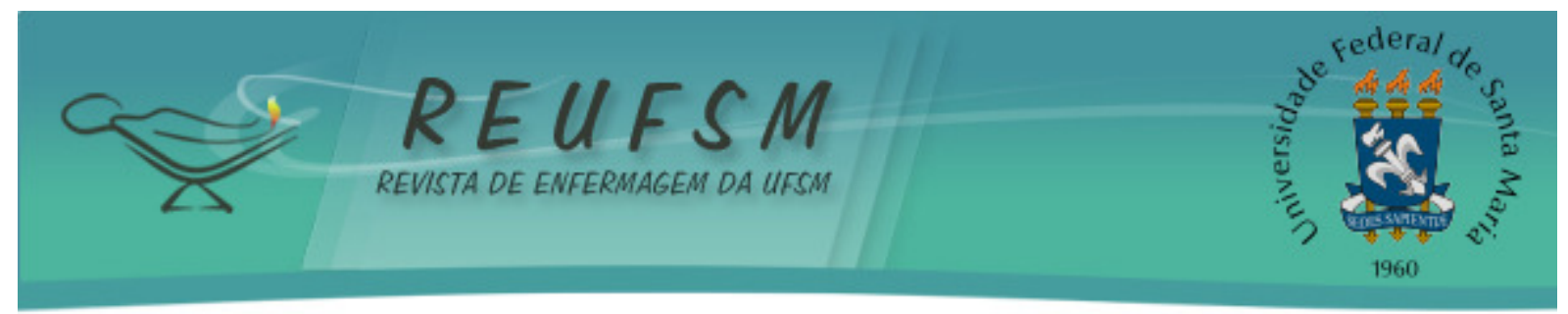

understanding, their meanings, myths and doubts.

Descriptors: Adolescent health; Women's health; Sexuality; Culture; Nursing.

RESUMEN: Objetivo: conocer los mitos y dudas de un grupo de mujeres adolescentes sobre los cambios corporales y sus implicaciones en la sexualidad. Método: estudio de campo, de tipo descriptivo, con enfoque cualitativo. Las participantes del estudio fueron nueve adolescentes femeninas. Los datos fueron colectados en una escuela primaria pública en un municipio de Rio Grande do Sul (Brasil), mediante técnica de grupo focal y analizados con análisis de contenido temático. Resultados: los eventos femeninos más comunes en el grupo estaban relacionados con la menstruación, como el síndrome premenstrual, menarquia y virginidad. Se entendió que ellos están dotados de significados socioculturales construidos en la convivencia social de los adolescentes. Conclusión: el estudio permitió una mejor comprensión de la influencia de la cultura en la experiencia de la sexualidad, demostrando la importancia de buscar, junto a las adolescentes, su comprensión, sus significados, mitos y dudas.

Descriptores: Salud del adolescente; Salud de la mujer; Sexualidad; Cultura; Enfermería.

\section{INTRODUÇÃO}

A adolescência é considerada como uma fase de transição e evolução na vida do indivíduo, delineada por transformações biopsicossocioculturais e pelo aparecimento de conflitos relacionados às incertezas e inseguranças, perda do papel infantil, busca de liberdade e de identidade própria. $^{1-3}$

Essa fase também é representada como um marco na construção da sexualidade, a qual é vivenciada de forma singular por cada sujeito. Quando se tratam de mulheres adolescentes, as quais apresentam um contexto histórico caracterizado pela repressão e pela diferenciação de condutas e de controles impingidos diferentemente aos homens, assim como pelas proibições, pela inferioridade e passividade, a sexualidade também é experienciada de forma diferenciada por cada uma..$^{3-4}$

Destaca-se também que a sexualidade é vivenciada no meio familiar de acordo com os valores apreendidos, pois é nesse ambiente que, desde a infância, são construídos e repassados ensinamentos e condutas socialmente aceitáveis, compondo o seu universo simbólico. ${ }^{4}$

Nesse contexto, encontram-se os mitos que são repassados na família. A palavra mito deriva dos verbos mytheyo (contar, narrar) e mytheo (conversar, nomear) e pode ser compreendido como uma história ou um conjunto de histórias que fazem parte da cultura de um povo e que são consideradas como verdadeiras, por serem proferidas por indivíduos que possuem autoridade e confiabilidade, sendo assim propagados por gerações. Na área da sexualidade, muitas vezes, os mitos podem confundir e provocar controles e limitações na vivência sexual. ${ }^{5}$

Dessa forma, o adolescente torna-se vulnerável às influências socioculturais, as quais podem ser visualizadas nas mais diversas transformações que singularizam o processo de adolescer. Ademais, entende-se que a construção da sexualidade é tanto individual quanto coletiva, pois se expressa e recebe influências, caracterizando-se de acordo com o contexto no qual o sujeito está inserido. ${ }^{6}$

Apresenta-se nesse artigo um recorte da pesquisa de dissertação de mestrado, que teve como questão norteadora: como os aspectos socioculturais influenciam na vivência da sexualidade de um grupo de mulheres adolescentes? Sendo o objetivo deste artigo conhecer os mitos e as dúvidas de um grupo de mulheres adolescentes em relação às modificações corporais e suas implicações na sexualidade. 


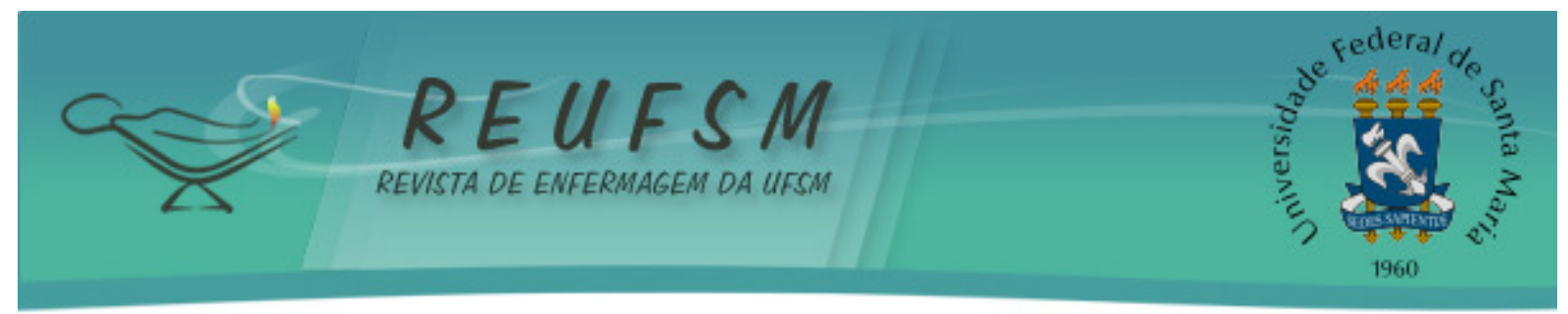

MÉTODO

Estudo de campo, do tipo descritivo, com abordagem qualitativa, ${ }^{7}$ pautada nos conceitos de cultura, ${ }^{8}$ que teve como cenário uma escola pública de ensino fundamental de um município do Rio Grande do Sul e como sujeitos nove adolescentes do sexo feminino. Os critérios de seleção das participantes foram: ser mulher adolescente (ter entre 12 e 18 anos), ${ }^{9}$ estudante da escola cenário do estudo, e moradora desta região. 0 critério de exclusão compreendeu adolescentes que tivessem limitações cognitivas, que as impossibilitassem de compreender e participar do estudo.

A coleta de dados ocorreu entre os meses de junho e julho de 2012, por meio da técnica do grupo focal, em três sessões. O grupo focal é um tipo de debate grupal, que permite maior interação e valoriza a comunicação intragrupo, com o objetivo de gerar dados e obter perspectivas diferentes sobre uma mesma temática. ${ }^{10} \mathrm{O}$ primeiro encontro teve como tema foco "ser adolescente" e no segundo e terceiro encontros, o tema foi "sexualidade". Para operacionalização da técnica, foram realizadas dinâmicas, sendo que no primeiro encontro foi utilizada a técnica de recorte e colagem, no segundo, a técnica de foto-linguagem e, no terceiro, algumas vinhetas.

Todas as sessões foram realizadas na sala de informática e percussão da escola, por se tratar de um local amplo, mais silencioso e no qual as adolescentes se sentiam à vontade. Ressalta-se que as sessões de grupo focal foram sempre com as mesmas participantes. A análise dos dados foi realizada por meio da análise de conteúdo temática ${ }^{7}$.

A pesquisa amparou-se pela condução ética, assegurando e valorizando os aspectos éticos e legais da Resolução $n^{\circ}$. 466/2012 do Conselho Nacional de Saúde Ministério da Saúde. A coleta dos dados foi iniciada após autorização da Secretaria do Municipal de Saúde; aprovação do projeto pelo Comitê de Ética da Universidade Federal de Santa Maria, sob o número de parecer 8931 e número do Certificado de Apresentação para Apreciação Ética (CAAE): 00555212.2.0000.5346, no ano de 2012; e também após a assinatura do Termo de Assentimento pelas adolescentes e do Termo de Consentimento Livre e Esclarecido pelos responsáveis pelas mesmas. Para preservar o anonimato das adolescentes foi utilizada a sigla $\mathrm{E}$, seguida de um número aleatório (E1, E2,...E9).

\section{RESULTADOS E DISCUSSÃO}

A partir da análise dos dados, buscou-se identificar nas discussões grupais, dentre as muitas transformações na adolescência, quais tiveram maior impacto ou eram lembradas pelas adolescentes como mitos relacionados à sexualidade. Dessa forma, apresenta-se, nesse artigo, a categoria “Crenças, dúvidas e mitos acerca da sexualidade". Assim, verificou-se a tensão pré-menstrual (TPM), a menarca e a virgindade como os eventos femininos mais significativos para elas, sendo dotados de símbolos e significados e construídos no convívio com a família e amigas.

Dessa forma, considera-se de extrema importância que os profissionais de saúde tenham conhecimento dos mitos que estão presentes no meio cultural das adolescentes e que podem influenciar em suas práticas de cuidado.

Observou-se que os mitos geram dúvidas em relação à sexualidade e cuidados com seus corpos. Um deles é relativo à TPM, que foi abordada em diferentes momentos dos encontros, como se percebe nas falas:

[...] mas se ela [a mãe da adolescente] estiver de TPM não dá pra falar com ela. Ninguém chega perto dela. (E1) 


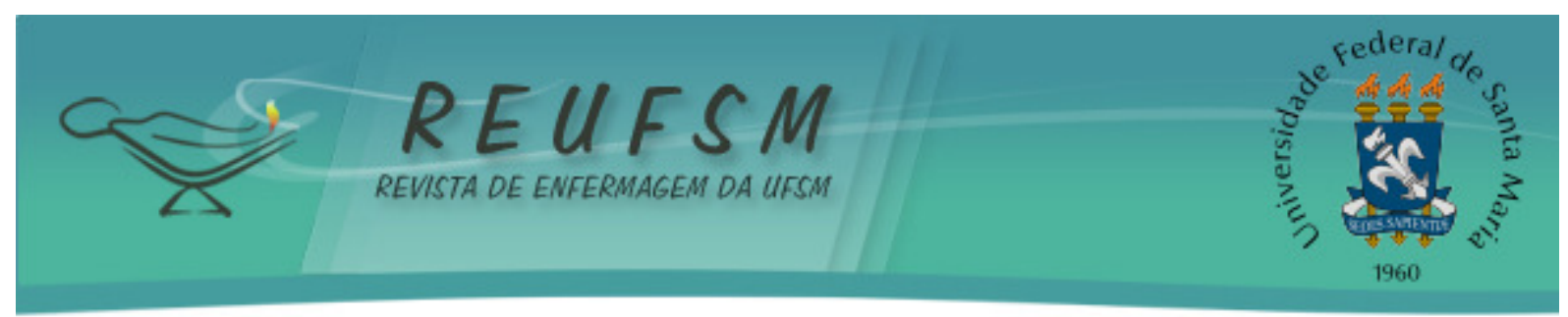

O meu tio, quando a minha tia está com TPM, ele sai de perto, ele tenta chegar mais tarde do serviço, ele tem medo. (E2)

[...] eu começo a xingar a minha irmã, puxo o cabelo dela [...] e fico meio irritada, meio braba, tudo está ruim, daí a minha mãe fala que eu vou menstruar. (E3)

Pior quando eu fui para praia, daí todo o tempo que eu estava lá, estava menstruada, daí queria matar todo mundo. (E4)

As adolescentes do estudo sabiam o que era TPM, e segundo elas, a maioria já havia apresentado sintomas referentes a este evento. Percebe-se nas falas das adolescentes que a mudança de humor das mães, tias e, até mesmo delas, é banalizada e é apontada como parte de um fenômeno socialmente aceito como TPM, que antecede a menstruação.

Essa banalização reflete uma concepção obsoleta que desnaturaliza a menstruação e atribui à mesma uma conotação negativa de agravo fisiológico, capaz de gerar desordens psíquicas que necessitam ser tratadas por meio da medicalização. Com isso, o ciclo menstrual deixa de ser considerado um evento natural e próprio do ciclo evolutivo da mulher e torna-se medicalizado e controlado. ${ }^{11}$

A menstruação pode ser um momento marcante na vida da mulher adolescente, sendo acompanhada de mudanças físicas, sociais e culturais. No entanto, esse acontecimento fisiológico pode ser visto como um problema, que se traduziu, no significado das adolescentes deste estudo, como uma declaração de que não gostavam de ficar menstruadas.

Menstruar é horrível. (E5)

É, cada um pensa de um jeito, tem mulheres que gostam e que não gostam [...] Eu acho muito nojento. (E6)

A gente não gosta de ficar menstruada, tu não tem aquela liberdade, tem que ficar se cuidando. (E3)

Observou-se que as adolescentes também atribuem à menstruação um sentido pejorativo, com conotação de algo nojento, que remete a cuidados especiais e a restrições no seu dia a dia, além do desconforto com as cólicas. Sendo vivenciado da mesma forma em um estudo semelhante da área de Enfermagem, no qual a menstruação também foi apresentada pelas adolescentes como um evento incômodo e sujo na vida da mulher. ${ }^{12}$

Logo, foi unânime, no grupo, a representação negativa do sangramento menstrual como algo ruim, vinculado à sujidade e à nojeira. A partir dessa concepção, a menstruação não é percebida como parte de um processo normal da fisiologia feminina, e sim como um momento de vergonha e desconforto à mulher. ${ }^{12}$

As adolescentes destacaram alguns mitos e cuidados especiais referentes ao período menstrual, que são culturalmente transmitidos em suas famílias:

E quando a gente está nos dias e chega perto da cozinha, a mãe não deixa chegar perto porque vai estragar tudo. (E1) 


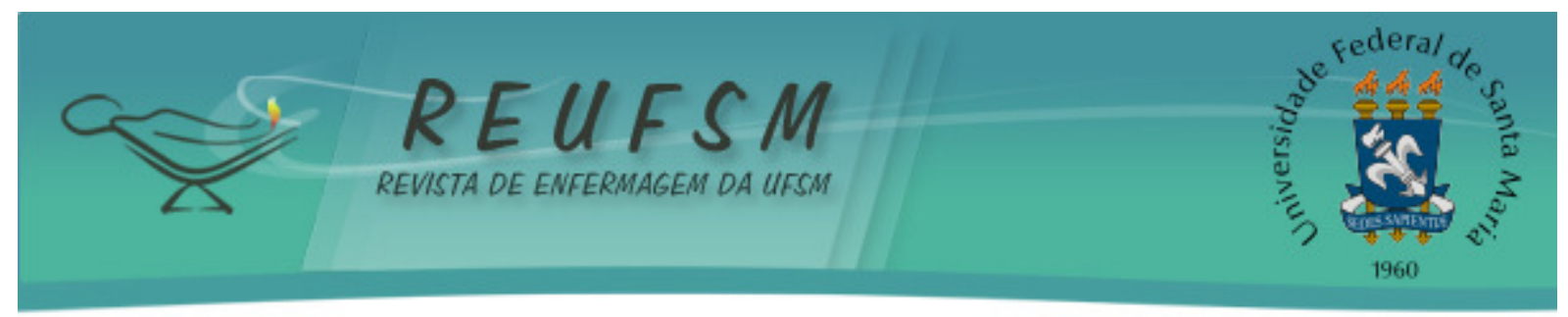

A mãe diz que não dá para lavar o cabelo no primeiro dia da menstruação, acho que é bobagem [...] (E7)

Destacaram que este estado "especial" pode interferir no preparo dos alimentos e na higiene pessoal delas. Estes conhecimentos e práticas de cuidados foram transmitidos para as adolescentes por suas mães na socialização primária.

Corroborando com estes achados, outro estudo também destacou que esses mitos perduram nos hábitos e práticas sociais resultando em diversas proibições, como lavar a cabeça, cozinhar, andar com os pés descalços, entre outros. ${ }^{12}$

Durante uma das sessões de grupo focal, utilizaram-se vinhetas com situaçõesproblema, a fim de estimular a discussão do tema entre as adolescentes. Após o debate de uma vinheta que expressava ausência de diálogo com os pais, que repercutia em equívocos sobre as modificações que ocorrem na adolescência, as participantes do grupo focal destacaram suas dúvidas acerca das mudanças corporais após a menarca:

Não me sinto muito bem por não ter menstruado ainda [...] porque minhas amigas estão criando peito, criando bunda, perna, e eu sempre do mesmo tamanho aqui. (E6)

Acho que isso não tem nada a ver. Eu não mudei nada [...] (E4)

Dizem que depois da relação sexual [...] e depois da menstruação a gente aumenta sim, cria "ancas". (E8)

As adolescentes demonstraram entendimento de que a menarca pode resultar mudanças físicas no corpo da mulher, mas que isso depende da especificidade de cada pessoa. Para elas, isso acontece naturalmente. Entretanto, as adolescentes que ainda não haviam tido a primeira menstruação relataram que se sentiam diferentes, principalmente, em relação às outras colegas. A maioria das adolescentes acredita que a menarca interfere no crescimento e desenvolvimento do corpo. Os comportamentos são impulsionados pelo conhecimento acumulado e representações sociais, das quais fazem parte as superstições e os mitos construídos em torno dos cuidados de saúde, ${ }^{13}$ nesse caso, da menarca.

Nessa perspectiva, alguns estudos destacam que essa fase marca o início do crescimento na estatura, desenvolvimento das gônadas e de características sexuais secundárias femininas (desenvolvimento das mamas, aparecimento e distribuição dos pelos pubianos), aumento na massa corporal, entre outros. ${ }^{2,14}$

Destaca-se a importância de proporcionar espaços para a discussão e orientação sobre sexualidade, modificações físicas e outras questões que permeiam a adolescência, incluindo os mitos e os tabus, de forma dinâmica e participativa. ${ }^{15}$

Para as adolescentes e suas famílias a menarca define-se como um rito de passagem. Contudo, elas relataram que não se sentiam bem com a polêmica que isso causava na família:

No dia que eu comecei a menstruar, minha mãe contou para todo mundo. [...] e não precisa que os outros fiquem sabendo [...] (E6)

[...] minha mãe contou pra minha tia, minha tia contou para meu tio, meu tio contou pro meu primo [...] (E4) 


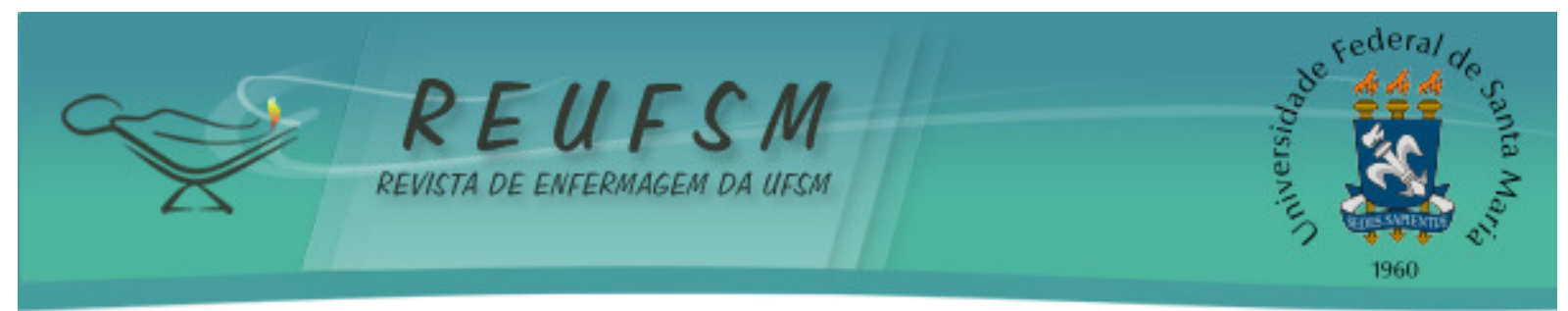

Percebeu-se que embora a primeira menstruação possa representar um marco na transição da fase infantil para a adolescência e seja comemorada e compartilhada por suas famílias, o comportamento familiar às constrange pela exposição social no grupo em que vivem. Contudo, para os familiares, a menarca representa uma fase de transição muito valorizada e significativa, pois a adolescente adquire um novo status perante o grupo e à família. $^{12}$

Nessa fase, também há a possibilidade de gravidez, a partir da menarca, o que representa um rito de passagem para a fase adulta e para o despertar da sexualidade, sendo um sinal corpóreo de feminilidade, que reforça o papel social predestinado a elas. ${ }^{12}$

Assim, a menstruação traz consigo as questões de responsabilidade, maturidade, maior confiança e maior liberdade frente aos pais.

Depois que fiquei menstruada minha mãe me liberou mais [...] (E9)

Depois que tu fica menstruada tu tem que criar juízo $e$ responsabilidade. (E2)

Percebe-se que vivenciar a menstruação, no universo das adolescentes representa um desafio, pois envolve transformações profundas no corpo, na mente e nos relacionamentos. Mais do que isso, a menarca apresenta-se como um evento marcante, pois simboliza o começo da capacidade reprodutiva e maior responsabilidade pela contracepção. ${ }^{16}$

Ainda em relação à responsabilização pela contracepção, alguns estudos confirmam a ocorrência desse achado e ressaltam que é comum que o mesmo incida majoritariamente sobre as meninas. Entretanto, destaca-se que nessa fase, assim com os meninos, as adolescentes não possuem maturidade e conhecimento suficientes diante de tamanha responsabilidade. ${ }^{12,17}$

Ainda, outro aspecto discutido durante os encontros foi o uso de absorvente íntimo, durante a menstruação, sendo elencado pelas adolescentes como uma dúvida:

Até dá para entrar na água se tu tiver um daqueles [...]OB. (E4)

Mas gurias virgens não podem usar, né? Uma amiga minha colocou, mas ela quase morreu gritando. (E9)

Uns dizem que perde a virgindade [...] eu prefiro nem ficar sabendo se perde ou não perde. (E5)

No estudo, as adolescentes demonstraram possuir conhecimento limitado do que é um absorvente interno, como se usa, como age e que efeitos são gerados a partir de seu uso. Todas apresentavam dúvidas em relação ao modo de usar, indicações e contraindicações, possibilidades pessoais, se perde ou não a virgindade, se provoca dor, entre outras. Evidenciaram curiosidade, porém, nenhuma delas relatou ter buscado orientação sobre isso. As informações que possuíam eram por troca de experiência com as amigas, sendo que nenhuma indicou os pais como promotores de esclarecimento de dúvidas quanto ao uso deste tipo de absorvente.

0 conhecimento acerca do absorvente interno estimulou, no grupo, contradições e expressão de dúvidas, por ser um produto de cuidado íntimo feminino pouco utilizado por elas. Vale ressaltar, mais uma vez, que os fatos pouco conhecidos, porém interpretados como verdades, são perpetuados pelas gerações como mitos. ${ }^{6}$ 


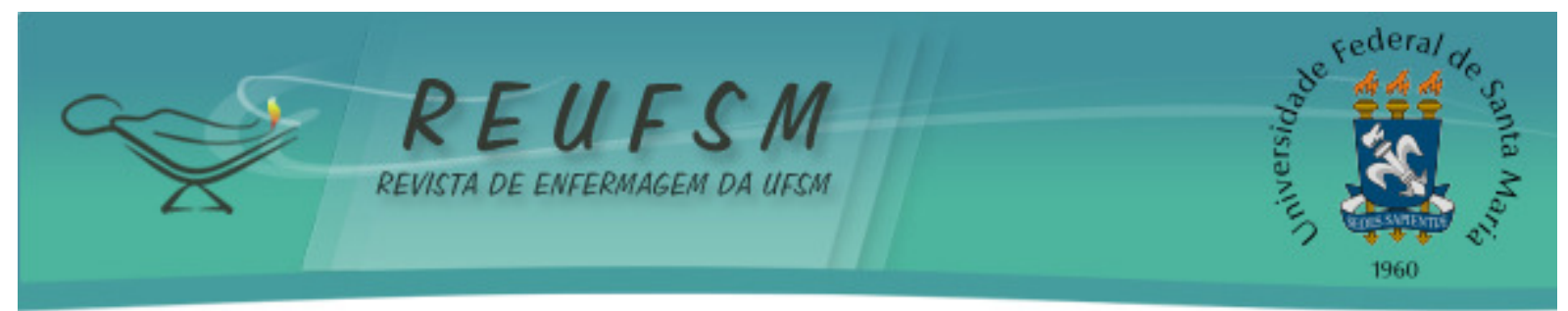

Ao realizar pesquisas sobre o absorvente íntimo, é possível encontrar na Internet muitos sites e informações sobre seu uso. Percebe-se que a disponibilização de informações com sentido errôneo, nestes espaços, pode influenciar na decisão de muitas mulheres em optar por não utilizar 0 absorvente íntimo como uma opção para a proteção durante o período menstrual. ${ }^{17}$

Ademais, as manifestações e normas comportamentais dirigidas às mulheres adolescentes são mais permeadas por conceitos sobre o que é certo ou errado, repercutindo diretamente na compreensão e na construção de sua sexualidade, e menos de esclarecimento em si, sobre os eventos de transformação física, mental e sociocultural desta fase de vida. Desse modo, compreende-se a sexualidade como um processo contínuo de aprendizado, descobertas e limitações. ${ }^{4}$

Destaca-se que, considerando o universo da adolescente, no que diz respeito às transformações relativas ao corpo e à sexualidade, essa pesquisa confirma estudo desenvolvido na área da Enfermagem que apresenta os pais distantes da esfera de orientação em relação à sexualidade na adolescência, participando pouco no esclarecimento de dúvidas, ou muitas vezes negligenciando-as, e favorecendo com isso o distanciamento de seus filhos. ${ }^{18}$

Acrescenta-se que a falta de preparo para as famílias para lidar com as mudanças vivenciadas pelas adolescentes dificulta suas condições de prestar uma assistência necessária às mesmas. Muitas vezes, os pais demonstram dificuldade em abordar as questões que envolvem corpo e sexualidade com seus filhos, justamente por não terem clareza dos acontecimentos vividos por eles próprios nesse período. ${ }^{19}$

Outro aspecto relativo à vivência da sexualidade na adolescência, e que é culturalmente permeada de mitos, é a virgindade. Ao questionar qual o significado de virgindade para as adolescentes, suas respostas foram:

Um guri perguntou no 'Altas Horas' [programa de televisão] para a médica e ela respondeu que é uma pelezinha bem fininha $e$ sensível, que qualquer coisa arrebenta. (E8)

Virgem é uma guria que nunca transou e nunca ficou com nenhum guri (risos). (E7)

[...] ser virgem é [...] tem dois sentidos: de ser virgem, e tem aquela pessoa que nunca beijou e ela é virgem de beijo, é beijo leve, BV, boca virgem. (E3)

Sobre este evento, há entendimento diverso, dúbio e orientado pela mídia. Esta tem auxiliado na elaboração de conceitos às adolescentes, uma vez que todas concordaram com o que foi dito no referido programa de televisão. Além disso, foi trazida a definição de virgindade relacionada a uma pessoa que nunca beijou, que nunca "ficou" com alguém e que um exame laboratorial de urina pode identificar se a pessoa é virgem.

Destaca-se que a televisão, como meio de comunicação de massa, investe na transmissão de mensagens que codificam modos de vida compatíveis com as normas vigentes da sociedade, e utiliza o papel de profissionais da saúde para darem confiabilidade científica para suas afirmações. ${ }^{20}$ Desse modo, a mídia ocupa diversos espaços em nossa sociedade, muitas vezes, desempenhando funções de esclarecimento, mas por outro lado também, prescritivas. Contudo, deve haver uma preocupação em relação a esses debates nos meios de comunicação, pois eles podem influenciar 


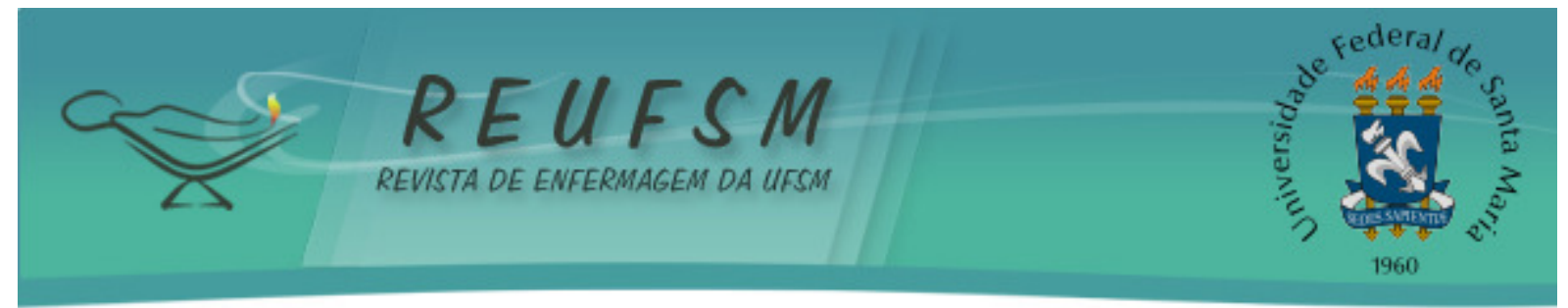

diretamente no comportamento dos adolescentes, muitas vezes, com informações distorcidas sobre a saúde sexual. ${ }^{21}$

Quanto às definições e conceitos que são organizados pelos adolescentes e envolvem questões de sua sexualidade, como neste estudo, - a busca do entendimento do que é virgindade para elas -, estudos da área da Enfermagem ressaltam a importância de os profissionais da saúde conhecerem essas definições para atuar de forma mais efetiva junto a esses grupos. ${ }^{22}$ Para tanto, é preciso considerar o contexto histórico, social e cultural em que vivem os adolescentes, não restringindo a sexualidade apenas à sua dimensão reprodutiva. ${ }^{23}$

Percebe-se que os questionamentos e as dúvidas das adolescentes relacionaram o significado de virgindade a uma conotação biológica, e que ser ou não virgem, para elas, depende exclusivamente da penetração vaginal. Elas afirmaram que mesmo uma pessoa que já teve relação oral ou anal, se não teve penetração vaginal, continua sendo virgem.

Se ela tem a pelezinha fininha ela ainda é virgem, mesmo se já tiver tido outros contatos (confirmação do grupo) [...] É se fez por trás e com a boca. (E4)

Foi possível observar que o conceito de virgindade ainda é estritamente biologicista para elas, e depende do tipo de relação sexual experienciada, ou seja, anatomicamente que órgão foi penetrado. Ademais, o início da prática sexual para as adolescentes traz uma série de dúvidas e tabus que as acompanham e podem aumentar a vulnerabilidade delas para o uso, ou não, de medidas preventivas, como preservativos. ${ }^{24}$

Estudo recente pondera acerca da sexualidade para o adolescente, dizendo que, apesar da facilidade de acesso à informação e ao conhecimento, o diálogo e a discussão de adolescentes e pessoas capacitadas e disponíveis para esclarecê-los e ajudá-los é imprescindível no entendimento de sua sexualidade. ${ }^{22}$

A virgindade feminina foi reforçada por muitos anos, e ainda é concebida socialmente, em muitos grupos sociais, como selo de garantia e motivo de honra para a mulher e sua família. Essa conotação vem perdendo tal significado, e não apareceu em nosso estudo, mas continua atrelada a muitos mitos e preconceitos, sendo incentivada tal perda para os homens e censurada para as mulheres solteiras. ${ }^{25}$

A sexualidade é ainda cercada de mitos, como herança do contexto históricosocial, influenciando a vivência da sexualidade. Esta temática ainda é uma questão polêmica e preconceituosa em nossa sociedade contemporânea e consequentemente no seio familiar. ${ }^{24} \mathrm{Na}$ prática, os mitos e as dúvidas ainda permanecem por várias gerações. Nessa direção, abre-se um amplo espectro de ação aos profissionais da saúde, para o esclarecimento de dúvidas e orientação aos adolescentes. Isso potencializa os espaços de discussão e troca de conhecimentos condizentes às suas dificuldades e contextos que podem qualificar, de maneira mais saudável, responsável, confiante e segura a vivência da sexualidade na adolescência, e consequentemente, na vida adulta.

\section{CONCLUSÃO}

A partir das dúvidas e mitos que foram desvelados no estudo, é possível um melhor entendimento sobre a influência da cultura que as adolescentes compartilham em relação à sexualidade. Dentre as transformações em relação à maturação sexual, verificouse que aspectos relacionados à menstruação, como a TPM, a menarca, e as práticas de cuidado durante este período; bem como a virgindade são eventos femininos simbólicos, dotados de significados, os quais foram construídos no convívio com a família, grupos de 


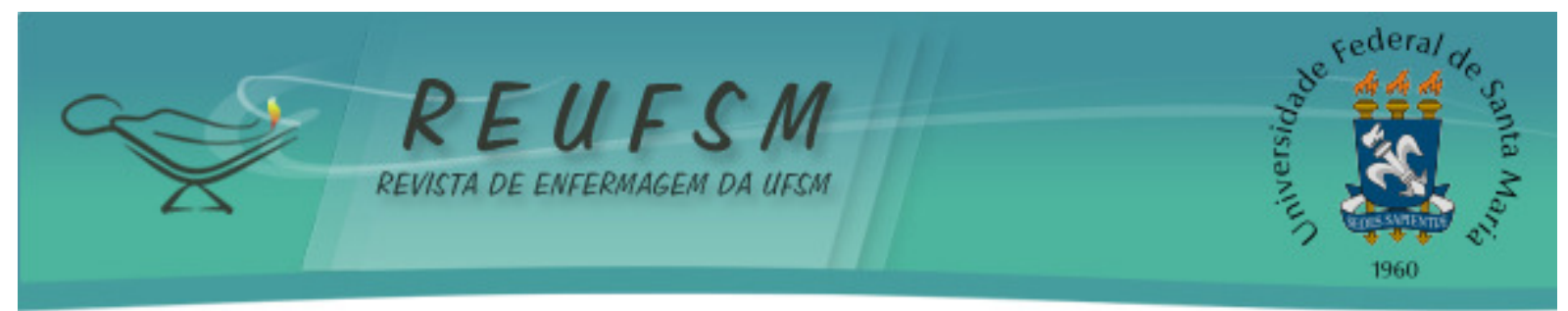

amigas e mídia. Esses entendimentos fazem parte da teia de significados que estas adolescentes teceram por meio dos símbolos presentes em sua cultura, sendo moldados no convívio social ao longo da vida.

Para estas adolescentes a tensão pré-menstrual é naturalizada como parte do processo da menstruação, e se relaciona principalmente à mudança de humor feminino; a menarca representa um rito de passagem para um período de maior responsabilidade e liberdade; a menstruação é percebida como algo desconfortável no dia a dia das adolescentes, relativo à sujidade e incômodo; e a virgindade é compreendida limitadamente a sua expressão biológica.

Estudar a sexualidade na adolescência, na perspectiva feminina, é ainda desafiante, pois há preconceitos e rótulos que envolvem esses dois eventos, gerando o risco de o profissional de saúde posicionar-se sob uma visão patologizante e determinista, que implica em interpretar, classificando e normatizando tais eventos com um significado de negação ou afirmação, ou seja, de normal ou anormal, e com isso se afastar da adolescente, perdendo a possibilidade de construção de uma condição de crescimento mútuo.

Destaca-se que este estudo demonstrou a importância de buscar, junto às adolescentes, sua compreensão, seus significados, suas dúvidas. Isso reitera que a adolescência deve ser vista não como um problema, ou uma fase de crise, mas como uma fase de possibilidades, de construção, de melhoramento, momento de aprendizado e crescimento tanto pessoal quando social.

Vale lembrar que, ao se investigar a adolescência não se encontram receitas prontas, mas sim caminhos que podem ou não servir, uma vez que há singularidades dentro de um mesmo grupo social, pois cada ser humano responde às demandas $\mathrm{e}$ às oportunidades da vida de modo único e de uma forma muito pessoal.

Salienta-se que as implicações deste estudo para a Enfermagem são relativas à essência da profissão, que é o cuidado. Ao assistir as adolescentes, o enfermeiro deve estar atento aos significados e percepções que elas têm acerca de seu papel social como mulheres e dos sentimentos e comportamentos em relação à sua sexualidade; considerar os seus interesses e seus conhecimentos prévios; e as envolver no planejamento e execução de ações de saúde que promovam o diálogo. É somente com essa visão integral que o enfermeiro prestará um cuidado humanizado.

\section{REFERÊNCIAS}

1. Oliveira LG, Brum ZP, Oliveira SG, Wünsch S, Garcia RP, Simon BS, et al. Oferta de serviços assistenciais aos adolescentes em seis municípios da $12^{\mathrm{a}}$ Coordenadoria Regional da Saúde. R Enferm UFSM [Internet]. 2011 [acesso em 2013 ago 14];1(3):335-42. Disponível em: http://cascavel.ufsm.br/revistas/ojs-2.2.2/index.php/reufsm/article/view/3584.

2. Moreira TMG, Viana DS, Queiroz MVO, Jorge MSB. Conflitos vivenciados pelas adolescentes com a descoberta da gravidez. Rev Esc Enferm USP. 2008;42(2):312-20.

3. Ressel LB, Sehnem GD, Junges CF, Hoffmam IC, Landerdahl MC. Representações culturais de saúde, doença e vulnerabilidade sob a ótica de mulheres adolescentes. Esc Anna Nery Rev Enferm. 2009;13(3):552-7.

4. Ressel LB, Junges CF, Sehnem GD, Sanfelice C. A influência da família na vivência da sexualidade de mulheres adolescentes. Esc Anna Nery Rev Enferm. 2011;15(2):245-50.

5. Chauí M. Convite à filosofia. 14a ed. São Paulo: Ática; 2010. 


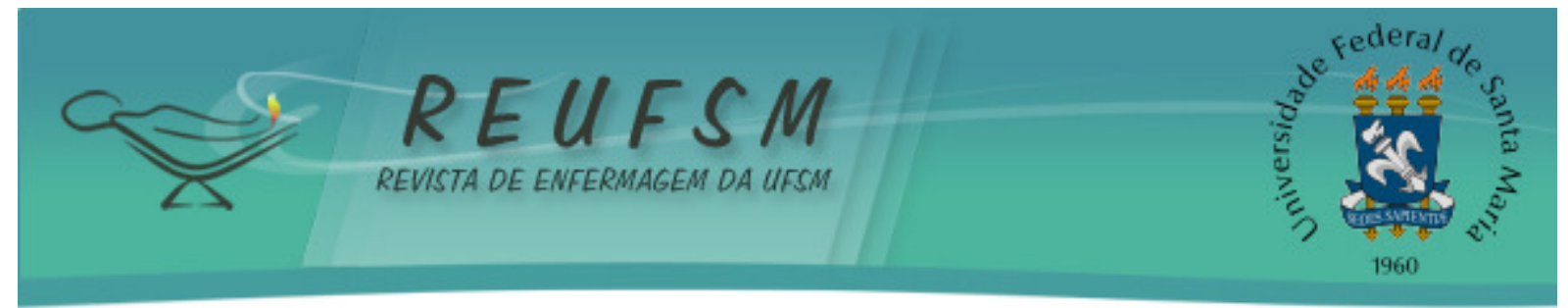

6. Moreira MRC, Santos JFFQ. Entre a modernidade e a tradição: a iniciação sexual de adolescentes piauienses universitárias. Esc Anna Nery Rev Enferm. 2011;15(3):558-66.

7. Minayo MCS. O desafio do conhecimento: pesquisa qualitativa em saúde. 12a ed. São Paulo: Hucitec-Abrasco; 2010.

8. Geertz C. A interpretação das culturas. Rio de Janeiro: LTC; 2008.

9. Brasil. Casa Civil. Lei $n^{\circ} 8.069$, de 13 de julho de 1990. Dispõe sobre o Estatuto da Criança e do Adolescente e dá outras providências [Internet]. 1990 [acesso em 2011 set 12]. Disponível em: http://www.planalto.gov.br/ccivil_03/leis//8069.htm

10. Kitzinger J. Grupos Focais: In: Pope C, Mays N, organizadores. Pesquisa qualitativa na atenção à saúde. 3ำ ed. Porto Alegre: Artmed; 2009. p. 33-43.

11. Vieira EM. A medicalização do corpo feminino. $1^{\text {a }}$ reimpressão. Rio de Janeiro: Fiocruz; 2008.

12. Brêtas JRS, Tadini AC, Freitas MJD, Goellner MB. Significado da menarca segundo adolescentes. Acta Paul Enferm. 2012;25(2):249-55.

13. Alvarez REC, Moncada MJA, Arias GG, Rojas TCS, Contreras MVI. Rescatando el autocuidado de la salud durante el embarazo, el parto y al recién nacido: representaciones sociales de mujeres de una comunidad nativa en Perú. Texto \& Contexto Enferm. 2007;16(4):680-7.

14. Meira TB, Moraes FL, Böhme MTS. Relações entre leptina, puberdade e exercício no sexo feminino. Rev Bras Med Esporte. 2009;15(4):306-10.

15. Martins CBG, Almeida FM, Alencastro LC, Matos KF, Souza SPS. Sexualidade na adolescência: mitos e tabus. Cienc Enferm. 2012;18(3):25-37.

16. Bouzas I, Braga C, Leão L. Ciclo menstrual na adolescência. Adolesc Saúde. 2010;7(3):59-63.

17. Santos CAC, Nogueira KT. Gravidez na adolescência: falta de informação? Adolesc Saúde. 2009;6(1):48-56.

18. Carvalho IS, Costa Júnior PB, Lima Neto AV, Freitas IN, Araújo RDT. A sexualidade em livros de ciências do 8- ano do ensino fundamental: uma abordagem satisfatória? Adolesc Saúde. 2012;9(3):29-36.

19. Brêtas JRS, Silva CV. Orientação sexual para adolescentes. In: Borges ALV, Fujimori E, organizadoras. Enfermagem e a saúde do adolescente na atenção básica. 1á ed. Barueri (SP): Manole; 2009. p. 210-48.

20. Junges CF, Ressel LB, Budó MLD, Padoin SMM, Hoffmann IC, Sehnem GD. Percepções de puérperas quanto aos fatores que influenciam o aleitamento materno. Rev Gaúch Enferm. 2010;31(2):343-50.

21. Miguel RBP, Toneli MJF. Adolescência, sexualidade e mídia: uma breve revisão da literatura nacional e internacional. Psicol Estud. 2007;12(2):285-93.

22. Freitas KR, Dias SMZ. Percepções de adolescentes sobre sua sexualidade. Texto \& Contexto Enferm. 2010;19(2):351-7.

23. Busanello J, Silva MRS, Oliveira AMN. Sexualidade na adolescência: realidade de uma comunidade rural. Rev RENE. 2009;10(1):62-71. 


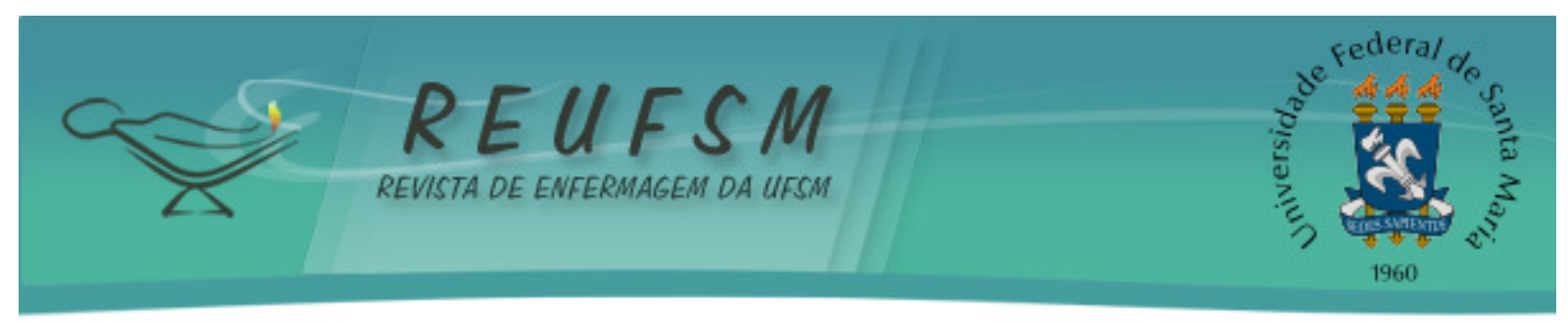

24. Mendonça GMM, Abreu LDP, Silva MAM, Andrade MP. Promoção da saúde sexual de puérperas adolescentes: conhecimento e práticas. Adolesc Saúde. 2012;9(2):14-20.

25. Soares SM, Amaral MA, Silva LB, Silva PAB. Oficinas sobre sexualidade na adolescência: revelando vozes, desvelando olhares de estudantes do ensino médio. Esc Anna Nery Rev Enferm. 2008;12(3):485-91.

Data de recebimento: $28 / 09 / 2013$

Data de aceite: $21 / 01 / 2014$

Contato com autor responsável: Lisie Alende Prates

Endereço postal: Programa de Pós Graduação em Enfermagem - Centro de Ciências da Saúde - Universidade Federal de Santa Maria

Avenida Roraima ${ }^{\circ}$ 1000, Prédio 26 - Cidade Universitária , CEP: 97105-900, Santa Maria (RS), Brasil.

E-mail: lisiealende@hotmail.com 